\title{
Resolving Healthcare Issues In Compliance With The Patient Protection And Affordable Care Act
}

Arthur K. Fischer, Pittsburg State University, USA

\begin{abstract}
This paper is an HRM case dealing with problems of a company resolving healthcare issues in compliance with the Patient Protection and Affordable Care Act. Discussion concerns how such a case can be used to exhibit the alignment between HRM strategies and legal mandates for healthcare benefits.
\end{abstract}

Keywords: HRM Case; Healthcare Benefits; PPACA; HRM Strategy

\section{INTRODUCTION}

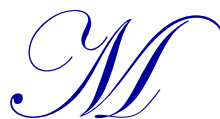

idwest Education, Inc. is a major supplier of educational materials for the United States. The company focus is on learning tools and systems for use in technology, science and business classrooms. In addition, it develops and provides books, manuals, videos, software and hardware used in the fields of technology education, instructional development and business applications.

The company has its headquarters and primary manufacturing plant in a major Midwest community. In addition, the Creative Development offices are located in Massachusetts and California. Transportation, Service and Maintenance facilities are headquartered out of Texas, with major branches in Baltimore and Phoenix.

The three main divisions exemplify three different strategies - cost-reduction, quality enhancement, and innovation (as discussed by Schuler and Jackson, 1987).

\section{Transportation, Service and Maintenance}

The primary strategy of the Transportation, Service and Maintenance Division is cost-reduction. Midwest Education, Inc. has long been known for providing service and maintenance programs which are very reasonably priced.

\section{Manufacturing}

The primary strategy of the Manufacturing Division is quality enhancement. Midwest education, Inc. has an enviable history of providing the highest quality products which have been adopted by first-rate schools and corporate training programs.

\section{Creative Development}

The primary strategy of the Creative Development Division is innovation. Midwest Education, Inc. is widely known for providing truly cutting edge teaching materials which always mirror the latest techniques and processes. 
Various HRM problems occur at these different facilities. These problems require students to develop responses and show how their responses can support the overall strategic plans of the division involved.

\section{COMPANY HISTORY}

Midwest Education was started by Henry and Mary Dalton in 1975. Dr. Henry Dalton was an industrial arts teacher before he got his MBA and went on to get his Ph.D. in Technology Education. Mary was a software developer who also taught business seminars. At that time, a new wave of emerging technology was beginning to alter the way people learn and communicate. By developing Midwest Education, Inc. the Daltons began work in an exciting new field. They found a vast market for quality tools that educated people on how to use all the new technology. Dr. and Mrs. Dalton are in semi-retirement now and travel extensively, but remain major shareholders in the business. They personally hired the CEO when they went into semi-retirement.

The company started with about fifty employees, but has grown consistently and now has a total of 416 employees within its three major divisions - 158 employees work in the Manufacturing Division, 123 work in the Creative Development Division and 135 work in the Transportation, Service and Maintenance Division. There are also 71 employees working at the headquarters in Kansas City (including the corporate staff).

At the beginning of the 1990s, it became apparent that international business was becoming the rule rather than the exception. The company went international in 1994 and now is exporting to three European, two Latin American, and two Pacific Rim countries. The Global Operations Division is located within the headquarters.

\section{Headquarters}

The corporate headquarters are in Kansas City. The CEO of Midwest Education, Inc. is Judith Lund. She was hired by the Daltons in 1994 when they decided to take a less active role in the company while remaining major shareholders. Ms. Lund has an MBA in business management and was previously the CEO of a small telecommunications company. In her previous position, she had successfully steered the company out of financial difficulties by raising stock value. She had initiated a strong advertising campaign and had put the company 'in the black' for the first time in seven years.

The COO of Midwest Education, Inc. is Frank Rose. He has been with the company since 1989. Mr. Rose, a cousin of Dr. Dalton, had a successful career with an international business training group in California. His desire to move back to his home town of Kansas City came at a time when the Daltons were looking for a COO. He has worked out well for the company.

The Human Resources Department is also located at headquarters. The Vice President for Human Resources is Lawrence Wilson. He has a degree in industrial and organizational psychology and an MBA and he has been with the company for 11 years. He started out as a generalist and was promoted as he showed good judgment with hiring and earned his MBA at the same time.

Within the Human Resources Department there are four sections:

1. Patrick Shew is the head of Staffing.

2. Compensation and benefits section is headed by Michael Martin.

3. Labor Management Relations is headed by Keith Lane.

4. Training, Career Development and Performance Appraisal is headed by Cynthia Burns.

There are also human resource specialists in each of the three divisions around the country.

\section{Manufacturing Division}

The mission statement for the Manufacturing Division is: "The aim of the Manufacturing Division of Midwest Education, Inc. is to continually improve the quality and strength of all our products. The superior products 
for which we have become world renowned will still be manufactured along with new and innovative products and ideas. We will work hard to keep quality high and cost down while supplying customers with the best possible products in the shortest possible time." The Manufacturing Division follows a strategy of quality enhancement.

The main manufacturing plant is located on the outskirts of Kansas City, not far from the company headquarters. The president of the Manufacturing Division is Max Thorn who has been with the company almost since its inception. He was one of the first employees hired by the Daltons. He started writing programs for the company and originally worked alongside the Daltons in interviewing and hiring many other employees.

The head of Human Resources for the Manufacturing Division is Janine Woods. She has a staff of five generalists who assist her in meeting HRM needs for the Manufacturing Division.

The Manufacturing Division used to be housed in the same building as the headquarters. As the business expanded and more room was needed, the division moved to the suburbs into a large factory. There are 158 employees in the Manufacturing Division. They are divided into ten teams with each team producing and packaging one specific product at a time. There are five supervisors who oversee two teams each - Doris Malone, John Fizer, Sandi Cross, Wendy Atchison, and Ian Carpenter.

The Manufacturing Division usually has a long lead time on orders and can anticipate what will be needed. The factory has flexible work areas that can be retooled and rearranged for the changeover from one product to another in less than four hours. The pay in this Division starts at $\$ 6.25 /$ hour for production workers and they have a full benefits package. Most employees seem happy with their work and Max Thorn is generally thought of as a good, easy-going man to work for.

\section{Creative Development Division}

The mission statement for the Creative Development Division is: "In the Creative Development Division of Midwest Education, Inc., we will strive to bring our customers the most innovative and cutting edge programs and products in the world. Our team of creative professionals is constantly working to improve, upgrade, and create the most useful products to bring to our customers." This division follows a strategy of innovation.

The Creative Development Division has two locations - a headquarters in California and a branch located in Massachusetts. The President of the Creative Development Division is Serena Tibaldo who recently joined the company. Previously, she was a software developer for a large computer game producer. She has a bachelor's degree in business and a computer programming master's degree, and she is doing very well at Midwest.

The head of Human Resources for the Creative Development Division is Amelia Chi, who is located at the California headquarters. Ms. Chi has a staff of five assistants. The head of the Human Resource section at the Massachusetts branch is Virginia Fox who has a staff of two assistants.

There are 90 people employed at the California plant and 38 at the Massachusetts location. The California location opened in 1980 and the Massachusetts branch opened in 1993. In the 1970's and 1980's, many computer software programmers moved to the west coast to be located in Silicon Valley. Most people hired by Midwest Education, Inc. transferred from wherever they lived to the California branch, with the company paying all relocation expenses. By 1990, some employees desired to live in the east. The Daltons decided it was time to expand the company and, in doing so, decided the next branch would be in the Massachusetts area. Most of the long-timers elected to remain California while the majority of recent hires are in Massachusetts.

\section{Transportation, Service and Maintenance Division}

The mission statement for the Transportation, Service and Maintenance Division is: "The Transportation, Service, and Maintenance Division is committed to providing the fastest and most cost-effective way of safely shipping our product to the customers. No effort will be spared as we streamline and improve our fast and friendly service". The Transportation, Service and Maintenance Division follows a strategy of cost-reduction. 
The Transportation, Service and Maintenance Division headquarters is located in San Antonio, Texas. There are major branches in Baltimore, Maryland and Phoenix, Arizona. The President of the Transportation, Service and Maintenance Division is Mark Derrick who is based in San Antonio. Mr. Derrick has been with Midwest Education, Inc. for 13 years. He personally hires the managers for the other branches in Maryland and Arizona.

The head of Human Resources for the Transportation, Service and Maintenance Division is Salvador Vasquez who has a staff of five assistants. Mr. Vasquez appoints HR heads to the other branches who are employees from San Antonio that he knows well and trusts.

The Transportation, Service and Maintenance Division was originally based in Kansas City. As the company grew, a decision was made to relocate the division to Texas. The other branches are newer, with Maryland opening in 1989 and Arizona in 1996. There are 55 employees in San Antonio and 40 in each of the other two branches.

\section{SITUATION}

Midwest Education, Inc. has been thrashing over many ideas as to how to respond to legal mandates under the Patient Protection and Affordable Care Act (ACA). At the direction of Frank Rose, COO, the Vice President for Human Resources, Larry Wilson, has conducted research into the law and gotten as much legal advice as he could. He even attended seminars that were advertised as helping companies determine how to respond and set up their compliance programs. He has discovered that there are many different options and much advice, but no one "right" way to be in compliance with the law. When he talked with Mr. Wilson about all the different possibilities and options, Frank decided to call together all of the interested players in the company and to finally make a recommendation to Judith Lund, CEO, as to how the company should respond.

At the meeting are the corporate COO and VPHR, with the head of the Compensation and Benefits Section sitting in as a technical advisor. The presidents and human resource heads from each division are present to provide input and represent each of their divisions' interests.

Frank Rose: Thanks to everyone for coming. I know it may seem that there are more important things for each of you to be worrying about, but we've got to come to some agreement on what our policy will be in response to the new "Obamacare" law. In my initial discussions with Ms. Lund, she has repeated how important it is to take care of our employees, and certainly good healthcare is an essential part of taking care of our employees. On the other hand, she is constantly emphasizing how our costs for everything are going up and how important it is to remain competitive in the marketplace. Looking at the mandates of the new law, it seems that we may have to start providing much more insurance coverage to more employees than we have been in the past, and this will greatly raise our overall cost structure. Even worse, there are more mandates than guidelines, and even new penalties for making a mistake or doing nothing! Very few people really understand the whole law, but we still have to comply. Then there's the question of how we want to comply. Should one size fit all? If that's the case, I could just make an executive decision you would all have to live with. On the other hand, you may have your own concerns, so I encourage everyone not to be bashful - speak out if you feel you can't live with some aspects of a proposed compliance policy.

I've asked Mike Martin to sit in because he will ultimately be responsible for implementation of whatever we decide. Mike, how about you giving us a brief rundown on what the law says and what our options are.

Michael Martin - Compensation and Benefits Section: Thanks Frank. I don't know how brief I can be in covering a 2,000+ page law, but I'll try. As you all know, this law passed in 2010 and gave until 2014 for full implementation, but the time is here when we have to decide what we are going to do.

At its foundation, the law is about ensuring that all Americans have some sort of healthcare insurance. It specifically states that employers with more than fifty employees (that's us) must provide health insurance to their full-time employees or pay at least a \$2,000 tax penalty for each employee (minus 30). I can remind you that health 
insurance at Midwest Education is somewhat spotty. I know, Mark, that you have chosen not to provide insurance for some of your part-time workers in the TSM division in order to keep costs down, and even some others are not providing insurance to our lowest paid employees. If we chose to not provide such insurance, then the employees will be required to get their own health insurance or they will pay a penalty; plus, if only one then gets a tax credit to supplement his or her own insurance, then we could still be fined. As you can see, the law has both carrots and sticks to make sure the government gets what it wants - full healthcare coverage for all Americans.

This year we are averaging a little more than \$10,000 per covered employee for health insurance when we include dependents, but there is wide variance. Under the ACA, there will be some range of policies that we can provide, but the less support we provide to our employees, the more we may have to pay as a tax penalty. In addition, in the past we could pretty well choose what policies we wanted to offer - benefit levels, coverage, and so forth - but now the government is telling everyone what must be included in all standard policies (with varying support levels: bronze, gold, diamond, and platinum).

Another kicker is that if a company does offer its employees health insurance, but for some employees that health insurance is unaffordable or does not provide minimum value (government decides standard), then that company can be fined. In this case, the penalty is the lesser of \$3,000 times the number of FTEs who are receiving a governmental premium assistance tax credit or $\$ 2,000$ times the total number of employees. This really means that you can't just have a pitiful policy and hope to skate by the coverage fines.

Salvador Vasques - HR, Transportation, Service and Maintenance Division: OK Mike, this sounds like so much government pressure to force every company to have at least minimum standard health insurance coverage, but what does it really mean for Midwest Education? I mean, what options do we realistically have? Do we have to just go along?

Michael Martin: As I see it, we can pay \$2,000 for every employee (minus 30) at Midwest Education and leave it to them to get their own insurance through the state exchanges where they live, but there are going to be plenty of employees - workers and management - who are going to be mighty unhappy with that alternative. On the other hand, we can go ahead and participate at whatever level we can afford or want to offer, but I know I'll need at least one new benefits specialist to monitor the program in my office.

Serena Tibaldo - Creative Development Division: Before we go any farther, I need to state emphatically that my division can't operate with just paying the fine and expecting my creative people to go out on their own and try to negotiate a good insurance policy. They want us to do the decision-making for them, and I'll guarantee that they expect the best! There is no way I could keep creative minds active and committed if they thought we were just throwing them to the wolves; and good luck finding anyone new to replace them if we're not offering decent health insurance.

Amelia Chi - HR Creative Development Division: I know it sounds as if we're always the division that's saying we must be the industry leader in pay and benefits, but it is getting very difficult to find good talent at any price. You all have good people who expect above average benefits, but for us it's a matter of necessity. It's hard enough to compete with Silicon Valley when they start throwing out stock options, free lunches, free childcare, and all the other wonderful things they offer; but if we don't have new ideas, we can't keep up with the technology we're trying to train the students on. We either keep current or we go out of business pretty soon.

Mark Derrick - Transportation, Service and Maintenance Division: I feel for you guys and appreciate your position, but we're constantly being bombarded to keep costs down. It almost seems as if every day I'm asked to cut something by one or two percent, and this new healthcare program certainly isn't going to reduce any of my costs. Right now, at least half of my stockers, drivers and loaders are close to minimum wage and they say that they can't afford for us to force them to take out insurance they don't need. Many have said that they could get work at smaller companies where nobody would be paying for insurance, or at least small companies can get a tax break for subsidizing their employee healthcare insurance policies. 
See where that leaves me? Even some of the guys who have been with us a while and are making higher wages want to keep what they've got and not have us start putting some of their compensation into insurance, especially the single one's who just don't think they need it right now. So I've got some that will leave if we shift money, or cost of living raises, to insurance, while others will go to smaller companies where they can get the same or a little more with a government handout.

Max Thorn - Manufacturing Division: There is at least one good option you have, Mark, that I'm really hesitant to try - non-full-time workers. There are a few areas where I could increase the number of assembly workers who don't work full-time. In fact, some family members have been asking about not having to work a full 40-hour week. But in the TSM Division, you must have a lot of jobs where you could work your people for 28 hours. Figure it out you could replace three full-time workers with four part-time workers without any real loss, and we wouldn't have to pay any penalty for part-time workers who don't have insurance. It would really lower the total cost of compliance iffewer of our workers qualified for insurance. What do you think, Mike; is that a good possibility?

Michael Martin: If you think about it, we probably have about a quarter of our staff who don't need to be full-time workers. Not everybody will be happy, but it would certainly reduce our exposure. Another idea might be to increase our use of seasonal workers. TSM and Manufacturing both have peak periods in the summer when you're making the fall goods and getting them delivered to the schools. It might not work for everything, but if we scheduled more of the fabrication and delivery for certain periods, then we could use employees who work less than 120 days a year, and thus wouldn't be counted against us. For every full-time job we can legally turn into a parttime, we could save the $\$ 2,000$ penalty and might make a no-insurance policy more attractive.

Mark Derrick: Hey, how about this - give me the authority to hire 120 day seasonal workers and I could use this for college interns. They're cheap and highly motivated, and I could probably use some of them to replace a low level manager or two to do projects and supervise other seasonal workers. That would really save some money. Amelia, do you think Virginia Fox in Boston would have good luck getting 120 day interns from MIT? What a sweet way to cut down on some of your overpaid creative types and still get the best and brightest new talent.

Amelia Chi: I can't believe that all you guys think about is money. Sure, it's important, but what about our brand image as the quality leader who always comes up with special new teaching tools? Wouldn't it be better to try to find ways of providing coverage that honestly helps our people be better at what they do? We could have a twotiered program where smokers and some obese employees pay a little more, which would encourage many of them to kick their bad habits and become healthier. In fact, we could even self-insure. As long as we meet the government standards, an in-house program could even be cost effective. What if we hired nurse counselors for each area and had them helping employees lead healthier lives? They could help with wellness programs of all sorts and make this a good place for healthy people to work. If we couple this with just trying to hire healthier people to start with, it could have a big impact and not be too expensive.

Frank Rose: Wow, what a lot of issues to think about. I was surely hoping it was possible, someway, to have a blending of all your ideas? How about we take a break and meet again tomorrow morning. Meanwhile, I think I need to talk with Judith and see if she has any guidance as to which direction she wants the company to take.

\section{QUESTIONS FOR STUDENTS:}

1. What kind of company is Midwest Education? What are its most important values?

2. There appear to be at least two different viewpoints represented. What are the advantages and disadvantages of each?

3. What outcomes would you expect if one or the other of these viewpoints is adopted?

4. Is there some way to resolve the differences in these viewpoints? 


\section{AUTHOR INFORMATION}

Dr. Art Fischer is a University Professor of Management in the Department of Management and Marketing at Pittsburg State University. He is a FELLOW with the American College of Healthcare Executives and is a retired healthcare executive. E-mail: afischer@ pittstate.edu 


\section{NOTES}

